\title{
Missing Women in India
}

\author{
Sanchi Jain
}

\begin{abstract}
The fast decline in the sex ratio and the excessive mortality of women corresponds to a major concern in India. Since the beginning of the 20th century, the number of men relative to that of women has been increasing in India. The change in sex ratio cannot be explained through poverty in India as poverty rate has been decreasing. India's economy has been growing at an increasing rate and the Economic Reforms of 1990's showed a significant impact on the growth and development of the country. Therefore, the concept of missing women in India has attracted attention over the years. These missing women died due to sex based discrimination in the society and unequal treatment in terms of resource allocation, medical care, food distribution and education. It is surprising that rising income and education levels have not been successful in solving the problem of declining sex ratio. Sex based discrimination has been highest among higher income households and states. The decline in sex ratio in India can be explained by various factors such as gender selective abortions, dowry deaths, female infanticide, strong son preference and differences in health and nutritional care. I argue that the prime reason behind it is the internalization of patriarchal values by the society even when income and educational levels increase.
\end{abstract}

Keywords - sex ratio, discrimination, education, son preference, patriarchy

\section{INTRODUCTION}

$\mathrm{T}$ HE fast decline in the sex ratio and the excessive mortality of women corresponds to a major concern in India. Since the beginning of the 20th century, the number of men relative to that of women has been increasing in India. The change in sex ratio cannot be explained through poverty in India as poverty rate has been decreasing. India's economy has been growing at an increasing rate and the Economic Reforms of 1990's showed a significant impact on the growth and development of the country as the GDP grew from $5.533 \%$ in 1990 to $7.107 \%$ in 2016 (World Bank 2017). Therefore, the concept of missing women in India has attracted attention over the years. This concept estimates the "additional number of females of all ages who would be alive if there had been equal treatment of the sexes among the cohorts that are alive today" (Klasen and Wink 2003). These missing women died due to sex based discrimination in the society and unequal treatment in terms of resource allocation, medical care, food distribution and education. Amartya Sen estimates the number of missing women in the regions affected by excess female mortality to be close to a 100 million (Ibid.).

The alarming rate of the women who have been missing is a matter of severe concern in contemporary India. It is

Sanchi Jain is a Master Student in University of Oxford, United Kingdom.(Corresponding Author Email: jainsanchi101292@gmail.com) surprising that rising income and education levels have not been successful in solving the problem of declining sex ratio. Sex based discrimination has been highest among higher income households and states. Unisa, Pujari and Usha (2007) estimate that "child sex ratios are the lowest ever in some of the some of the affluent states of the country situated in northern parts of India". The decline in sex ratio in India can be explained by various factors such as gender selective abortions, dowry deaths, female infanticide, strong son preference and differences in health and nutritional care. I argue, that the prime reason behind it is the internalization of patriarchal values by the society even when literacy rate has increased from $65 \%$ literates in 2001 to $74 \%$ in 2011 (Census of India 2011).

I have divided my essay into four sections. The first section discusses the impact of son preference and rise in dowry practices in India on the decline of number of women. The problem of sex selective discrimination is the second section of my essay which charts out the sex based differentiation in terms of food, health, clothing and education among girls and boys in a household. The third section of my essay focuses on the differentiation between North India and South India in terms of sex ratios and gender discrimination. The final section of my essay highlights some of the solutions to the issue of sex based discrimination and missing women in India.

\section{SON PREFERENCE AND DOWRY PRACTICES}

Social and cultural factors play an extremely important role even when the economy grows. This is evident through the impact of son preference on the fertility and mortality rate in Indian society. Arnold, Choe and Roy (1998) discuss the religious utility of sons in performing the last rites of the deceased, their role in helping the dead to achieve salvation of the soul through Hindu rituals. Girls, on the other hand, become an economic liability on the family. Even Gupta (1987) highlights the issue of rising son preference in Punjab which is the "outcome of women's structural marginalization" in society. Son preference for Gupta (1987) seems to be more culture driven and not primarily because of the economic hardship of a family. These social and cultural factors function as prime reasons behind gender bias in society and the "scarcity of resources may at most accentuate the effects of sex bias in a given culture" (1987). Religious and social mandates place women in an inferior position to men and also exclude them from rights of ownership, control of resources and decision making in the family. As the household gets richer, 
the women of the family are withdrawn from the labour force. Therefore, when the economy grows, lower castes are able to afford dowry and women belonging to rich households are restrained from working outside. Hence, the economic burden due to women in the family increases.

Srinivasan (2005) says that even "economic reforms of 1990's has not blunted son preference or done away with discrimination against girls and boys". The rise in dowry practices in India have led to a massive decline in sex ratio and have increased female infanticide and female suicides. Srinivasan (2005) in his essay discusses the issue of changing nature of dowries over the years. Dowry in the earlier times constituted items of utility and it was a voluntary gift by the parents to the daughters. On the contrary, in the contemporary times, dowries have become a means of transaction in order to extract gold, modern household gadgets and luxurious items from the bride's family. Nowadays, dowries signify opulent lifestyle, commercialization and modernization due to technological changes and transformation of people's aspirations. Women are therefore seen as an economic liability to the family due to the burden of dowry, which is considered as an essential factor for upward mobility through marriage. Another problem is faced due to Sanskritization, through which lower caste groups adopt the norms of the higher castes. Therefore, the dowry practice spreads to the lower castes and as a result, there is a massive increase in dowry deaths because dowry has become a "pan- Indian phenomenon" (2005), spreading to all castes and classes in India. It is paradoxical that dowry which is seen as a gift to achieve marital happiness, leads to the extermination of women from society. Women lack the ability and agency to go against this unjust social practice as this would involve humiliation and family dishonor. Hence, dowry functions as one of the major factors behind declining life chances of women.

\section{EX SELECTIVE DISCRIMINATION}

Other factor that leads to the declining life chances of women in India involves the gender specific discrimination against females. Gupta (1987) discusses the natural tendency of the family to give preferential treatment to the male child in terms of allocation of food, clothing and medical expenses. There persist differences in medical expenditure incurred for boys and girls in a family. Expenditure on boys is twice as much as that for girls on medical care in the age group of 0-1 year and the expenditure on clothing is greater for boys in all age groups. Medical expenditure on a male child is 2.34 times higher than a female child. Gupta's (1987) study highlights the neglect towards girl child in their upbringing and nutrition as opposed to the male child. Girls are fed with more cereals, whereas boys are fed with more milk and fat which involve high cost and high nutritional quality. Hence, the rising mortality of females is a result of the discrimination against females with respect to food and health care benefits. Girl children have been found to have very poor nutritional level and deaths of the girl child have also been recorded due to unfavorable weather conditions because of lack of proper clothing. Mishra, Roy and Retherford (2004) also discuss the issue of gender discrimination in terms of childhood feeding, immunization coverage and nutritional status. Boys are generally more breastfed, fully immunized and more efficiently treated against diseases than girls. Boys are also frequently taken to doctors for regular medical check- ups and hence they derive more nutritional and health benefits unlike girls.

It is evident that gender discrimination has persisted even after the introduction of various changes in the society such as "improvement in income levels, nutritional levels, health care and delivery and a variety of modernizing forces such as rapid increase in female education" (Gupta 1987), which could have helped to put a stop to the issue of female discrimination in society. I would argue that it is primarily due to the internalization of patriarchal values by the women themselves, that gender discrimination amongst girls and boys is normalized. Usually, an increase in level of education and awareness among women in India, would have resulted in equal care of children from both sexes. But the internalization of strict societal norms explains the prevalence of sex based discrimination and differential care for boys and girls even among educated women. Hence, "the women continue to want one to two living sons as they are under greater pressure not to have more than one surviving daughter" (Ibid.). Social and cultural factors have also led to the increase in the use of contraception amongst women which shows their strong son preference. These family values which see boy as a future economic security and girl as an economic liability are deeply entrenched in the minds of men as well as women that result in sex differentials in almost every household in India.

The internalization of gender stereotypes has also led to an increase in the sex selective abortions in India. Unisa, Pujari and Usha (2007) discuss the misuse of technology and its disastrous effects on the sex ratio in India. The introduction of technology to detect genetic abnormalities and sex determination in the latter half of the 20th century has made sex selective abortion a matter of serious concern. Even when the Prenatal Diagnostic Techniques Act 1994 banned the availability of facilities for sex determination, the laws have failed to be efficient in a society that is strictly governed by patriarchal values. Ministry of Health and Family Welfare 1996 reports legal abortions at about 0.6 million annually and illegal abortions to be 8 to 11 times as high as legal abortions (Ibid.). Sex discrimination is also evident in the preference of families and especially women to educate boys more than the girls as boys give financial security to the family in future. The spread of technology has led to increase in the number of women going for ultrasounds to know the sex of the baby. The increase in use of this technology has induced sex selective abortions in India. Since the tests are expensive, the rise in number of women who take these tests also signify the increase in family income. This further validates the issue of internalization of values and blindness towards gender equality in society. 


\section{NORTH AND SOUTH DIVIDE}

Sex ratio and sex based division also depends on demographic factors. The number of missing women and sex ratios in North India has been estimated to be different from that of South India. The Planning Commission in 2002 estimated the number of females per 1,000 males in Uttar Pradesh to be 898 and 964 females per 1,000 males in Karnataka (Rahman and Rao 2004). The cultural divide between north and south explains this variation in ratios. It is believed that the gender equality and sex discrimination differs in North and South of India. In South India women enjoy greater autonomy and freedom because of the South Indian culture of endogamous marriage which strengthens women's kinship network (Ibid.). Even Dyson and Moore (1983) distinguish between marriage patterns in North and South India. South India favours marriage between cross cousin whereas in North Indian marriages, spouses are unrelated as marriage is exogamic and women are not entitled to inherit property. Dowry is also not essential in South Indian marriages and wedding expenditure is shared equally between both families, unlike in North India where dowry has utmost significance in formation of new social relations. The stark differences between marriage practices on opposite sides of the country explain the differences in female autonomy and participation.

The index of son preference also varies between north and south. It is highest in Punjab which is calculated to be 31.3, whereas it is 11.5 in Tamil Nadu (Dyson and Moore 1983). Researches prove that the female autonomy is less in North than in South because female movement is curtailed in North India. South India gives more freedom to women in terms of family decision making, fertility, food distribution, social movement and education. As discussed earlier, Gupta (1987) analyzes Punjab's sex ratio to be most unbalanced and has the highest rate of sex based discrimination. Northern India records higher rate of female mortality due to discrimination against girls for medical treatment, food allocation, education and nutritional status. The women are therefore marginalized and are in low position to influence family decisions concerning fertility and children's upbringing. Hence, the contrast within India between North and South on the basis of sex differentiation and female autonomy is one of the major reason that explains the decline in life chances of women.

\section{V.CONCLUSION}

After analyzing the above factors that have been significant in the declining life chances of women in India, major attention towards gender discrimination is needed. The internalization of patriarchal values by the men and women in society has been the root cause behind the declining sex ratios. Some measures could be taken to solve this problem of sex selective discrimination. Firstly, if women are given a right to inheritance legally and practically, then the problem of dowry deaths could be checked. Secondly, there should be awareness among parents for the equal treatment of girls and boys. Girls should not be seen as an economic burden for the family, they should rather be seen as an equal to male members of the family. Thirdly, the enactment of the laws would not be successful until the structure of patriarchy is questioned and toppled. Failure to do this would not stop the rise in illegal sex selective abortions and female infanticide. Lastly, with the increase in income and education, the misuse of technology has been rapidly increasing. To curb this, the cultural factors that celebrate the religious and social utility of the male have to be challenged.

\section{ACKNOWLEDGMENT}

I am grateful to my Professor Dr. Matthew McCartney, University of Oxford for his constant support and timely guidance. I would like to express my special thanks to Sonnet Sarker for his encouragement and inspiration to complete this paper.

\section{REFERENCES}

[1] Arnold, F., Choe, M.K. and Roy, T.K., "Son preference, the familybuilding process and child mortality in India". Population studies, 52(3), pp.301-315, 1998.

[2] Census of India, (2011). State of Literacy. [Online]. Available at $<\mathrm{http}: / /$ censusindia.gov.in/2011-provresults/data_files/india/Final_PPT_2011_chapter6.pdf>

[3] Dyson, T. and Moore, M., "On kinship structure, female autonomy, and demographic behavior in India". Population and development review, pp.35-60, 1983 .

[4] Gupta, M.D., "Selective discrimination against female children in rural Punjab, India". Population and development review, pp.77-100, 1987.

[5] Klasen, S. and Wink, C., " Missing women": Revisiting the debate. Feminist Economics, 9(2-3), pp.263-299, 2003.

[6] Mishra, V., Roy, T.K. and Retherford, R.D., "Sex differentials in childhood feeding, health care, and nutritional status in India". Population and development review, pp.269-295, 2004. 